Edilasir Altina de Araújo Afonseca, Maria Teresa

Rodrigues Moraes, Miracy Barbosa de Souza

Gustin e Sônia Lemos Grandi, são técnicas da diretoria de planejamento social e urbano da Fundação joão Pinheiro, Belo Horizonte.
Edilasir Altina de Araújo Afonseca

Maria Teresa Rodrigues de Moraes

Miracy Barbosa de Sousa Gustin

Sônia Lemos Grandi

\title{
Dinamização do setor informal como estratégia de atuação no mercado de trabalho: uma análise da experiência mineira
}

\section{Introdução}

A inexistência de uma política nacional de emprego tem levado uma série de estados brasileiros a dimensionarem, através de seus órgãos de planejamento e execução, programas e projetos que possibilitem minimizar os efeitos negativos da presença de um elevado contingente populacional em situação de desemprego aberto e subemprego.

Não por casualidade mas por determinação de caráter estrutural, essas situações atingem majoritariamente a população de baixa renda que, devido suas caracteristicas sócio-econômicas e culturais, se tornam mais vulneráveis às conseqüências geradoras e resultantes da defasagem entre oferta e demanda da mão-de-obra no mercado de trabalho. Este tende a apresentar um número limitado de vagas e, paralelamente, a aumentar as exigências com relação aos requisitos a serem preenchidos pela força de trabalho.

As ações implementadas pelo Estado com relação à problemática de emprego podem ser dirigidas tanto ao setor formal quanto ao setor informal do mercado de trabalho.

A importância que vem sendo atribuida ao setor informal revela não só incapacidade do Estado em colocar em prática políticas específicas para o se- tor formalizado do mercado de trabalho, bem como a idéia que se tem da possibilidade de aumentar a capacidade de absorção produtiva de mão-de-obra excedente por intermédio de programas cujos objetivos se voltem à organização e dinamização do setor informal.

Tal concepção teve origem nas evidências empíricas resultantes da pesquisa realizada pela Organização Internacional do Trabalho no Quênia, quando da análise sobre os aspectos de emprego. Estudos efetivados no Brasil têm reiterado as proposições daquela pesquisa no sentido de que o setor informal cumpre um papel importante na dinâmica do mercado de trabalho, pois propicia oportunidades de emprego e renda aos seus integrantes.

\section{A abordagem da problemática pela} Secretaria do Trabalho de Minas Gerais

Em Minas Gerais, a organização e dinamização do setor informal do mercado de trabalho foram concebidas dentro dos objetivos propostos pelos projetos especiais derivados do programa estadual de emprego - SINE/MG - , sob a responsabilidade do Departamento de Trabalho, pertencente à Secretaria de Estado do Trabalho, Ação Social e Desportos. 
Para se ter uma melhor apreensão do significado desses projetos cumpre apresentar, mesmo que de forma sucinta, o conjunto dos programas vinculados direta e indiretamente à problemática de emprego, sob a responsabilidade desse órgão de estado.

O Programa de Desenvolvimento Acelerado de Mão-de-obra tem como meta final integrar o homem no processo sócio-econômico e cultural através de sua promoção profissional. Tem, ainda, como objetivos a promoção de cursos de qualificação e aperfeiçoamento de recursos humanos para mitigar os problemas detectados nessa área, a nível de mercado de trabalho. Promove cursos de reciclagem para o pessoal que atua diretamente no processo de capacitação, procurando, além disso, elaborar metodologia específica de trabalho e desenvolver pesquisas de ocupação.

Em alguns cursos de qualificação oferecem-se bolsas-ferramenta para o pessoal treinado. Isso ocorre principalmente quando os egressos têm maiores possibilidades de desenvolver suas atividades ocupacionais no setor informal do mercado de trabalho, na situação de trabalhador autonômo.

Pelo exposto, esse programa tende a cumprir uma função estratégica em termos de qualificar profissionalmente a população menos favorecida, para aumentar suas possibilidades de alocação produtiva no mercado de trabalho. O não-acompanhamento do pessoal treinado, todavia, implica em não se saber até que ponto esse contingente é absorvido pelo setor formal ou consegue desenvolver, com sucesso, suas atividades no setor informal.

Da análise desse programa de treinamento depreende-se que o mesmo apresenta um rol de possibilidades e limitações. Não obstante, acreditase que a eficácia dos cursos ficaria parcialmente garantida se parte do pessoal treinado pudesse ser absorvida no programa relativo à formação de microunidades de produção de bens e prestação de serviços, ou seja, que houvesse uma maior interligação entre os dois programas.

O Programa Estadual de Emprego SINE/MG define-se como subsistema do Sistema Nacional de Emprego, criado pelo decreto federal $n^{\circ} .76 .403$, de 8 de outubro de 1975. É dentro desse programa que são observadas as ações do Estado mais diretamente ligadas à problemática de emprego e onde, subseqüentemente, são colocadas as diretrizes da criação e implementação de ações específicas tanto para o setor informal do mercado de trabalho como para seu setor formalizado.

Um de seus subprogramas voltados ao setor formal diz respeito às atividades de levantamento $e$ veiculação de informações sobre oferta e demanda de mão-de-obra e oportunidades de aprendizagem profissional. Outro, dentro desta mesma linha, trata de intermediação entre pessoas que procuram trabalho e unidades produtivas que requerem mão-deobra e, ainda, têm competência para fornecer car teiras de trabalho.

Essas atividades são desenvolvidas em suas unidades operativas locais constituídas pelos núcleos microrregionais de emprego. Esses núcleos encaminham mensalmente dados e relatórios sobre oferta e demanda de mão-de-obra ao Núcleo de Operação do Departamento de Trabalho.

Com relação a esses subprogramas cabe fazer algumas considerções a fim de indicar a fragilidade das ações por parte do Estado em direção ao setor formal. Neste sentido, a análise de sua dinâmica de funcionamento e dos resultados apresentados revelam alguns aspectos, dentre os quais cabe ressaltar: a) o número de candidatos inscritos por ocupação é, sempre, muito superior ao número de vagas existentes; b) há uma queda substancial de candidatos quando se compara o número de inscritos e de encaminhados - o que significa que, dentre muitos, poucos são os que apresentam as condições mais gerais para preencherem as vagas segundo os parâmetros de seleção adotados pelos técnicos dos núcleos microrregionais de emprego; c) o número de candidatos efetivamente colocado é bem inferior ao verificado no caso anterior; d) mesmo com relação aos candidatos colocados, os núcleos não dispõem de meios para fazer com que as empresas cumpram os itens por elas indicados quando da oferta das vagas, tais como: salário, horário de trabalho, local, transporte, refeição, assistência médica, alojamento etc. ; e) comum é o fato das empresas apresentarem um número de vagas superior ao que elas realmente têm para oferecer; f) resta considerar ainda que, nos centros urbanos desenvolvidos, as atividades de intermediação são majoritariamente realizadas por agências particulares, que, por terem seus servicos remunerados, têm maiores possibilidades de colocar seus candidatos nas poucas vagas existentes. Por outro lado muitas empresas - geralmente as de maior porte - têm seus próprios departamentos de recrutamento e seleção, não fazendo uso dos serviços prestados por terceiros

Com relação às atividades dos núcleos voltados ao encaminhamento dos candidatos para os cursos de treinamento e qualificação, verifica-se a mesma situação anteriormente assinalada, ou seja, não se sabe das possibilidades de inserção produtiva, no mercado de trabalho, dos elementos que participaram dos cursos. 


\section{A implantação de microunidades de produção como projetos especiais}

A atuação desses subprogramas do Programa Estadual de Emprego é muito limitada e é uma das razões pelas quais os projetos especiais, geradores das microunidades de produção como estratégia de intervenção no setor informal do mercado de trabaIho, vêm ganhando destaques dentre os demais projetos e programas concernentes à geração de emprego e renda.

Analisando o histórico dos projetos especiais dentro da Secretaria do Trabalho, observa-se que, mediante eles houve após 1980 um crescimento significativo de microunidades de produção de bens e prestação de serviços contemplados por esses projetos.

A implantação da primeira microunidade foi em 1977. Em 1980, quando se realizou uma avaliação desses projetos pela Fundação João Pinheiro, havia quatro microunidades de producão voltadas à confecção de roupas em geral, uma lavanderia comunitária e uma cooperativa regional de trabalho localizadas em diferentes cidades de Minas, inclusive em Belo Horizonte.

$\mathrm{O}$ apoio às microunidades de produção por parte do Departamento do Trabalho tem se traduzido, desde o início, em assessoria técnica junto às entidades conveniadas, efetivada através de visitas, reuniões, correspondências e contatos telefônicos entre a equipe responsável pelos projetos e os elementos envolvidos nas atividades lentidades executoras, supervisores e/ou gerentes e integrantes dos grupos de trabalho diretamente ligados à produção). Inclui também o repasse de recursos para aquisição de material de consumo, equipamento e material permanente, ferramental de trabalho e remuneração de serviços e encargos.

As entidades nas quais as microunidades se apóiam juridicamente são, de modo geral, de caráter promocional e assistencial. Para que seja estabelecido o termo de cooperacão entre as entidades e - Departamento do Trabalho, exige-se como prérequisito o registro de entidade de assistência social, no Departamento de Acão Social também pertencente à Secretaria do Trabalho.

Essas considerações sobre os projetos especiais evidenciam que a experiência mineira de intervenção no setor informal do mercado de trabalho é bem recente. E o crescimento numérico das microunidades beneficiadas parece indicar que se trata de um conjunto de projetos sumamente válidos, sobretudo porque oferece à população de baixa renda a oportunidade de consolidar seus postos de trabalho com melhora significativa na qualidade e quantida- de dos produtos e serviços prestados e, conseqüentemente, aumento no nível dè renda.

Esses foram os aspectos positivos obtidos pela análise avaliativa das primeiras microunidades de produção e prestação de serviços implementados pelos projetos especiais. Além disso, detectaram-se também alguns pontos de estrangulamento de natureza econômica, física, social, jurídica e ideológica.

Dentre os aspectos negativos, os que mais se destacaram na análise foram os de ordem jurídica e econômica.

Na esfera econômica, podem ser apontados os seguintes dados: falta de capital de giro a impossibilitar a formação de estoque; indefinição da linha de produção a influir diretamente nos níveis de produção e produtividade; crescimento insuficiente da produção e produtividade, estreitamente vir.culados à indefinição da linha de produção, à formação profissional, às falhas de racionalização das atividades e à escassez de equipamento. Ademais identificaram-se problemas relativos à comercialização e divulgação.

Os aspectos de natureza jurídica referem-se, basicamente, à inexistência de personalidade jurídica por parte dos grupos de trabalho, dando oportunidade a que os recursos a eles destinados sejam repassados para instituições já regulamentadas, quase sempre entidades assistenciais, mormente religiosas.

Nesse caso, a emancipação dos grupos, ou seja, a sua transformação em associação ou cooperativa de trabalho - objetivo máximo proposto pelos idealizadores dos projetos - vai depender, em grande parte, da forma de atuação dessas entidades como executoras do projeto.

Essa não-regulamentação jurídica, no caso das primeiras seis microunidades analisadas, impossibilitou a detenção de talonário, com reflexos imediatos no processo de comercialização e com sérias conseqüências nos processos de produção, produtividade e divulgação das atividades.

De 1979 a 1981 houve um aumento expressivo no número de microunidades implementadas pelos projetos especiais. Um total de 32 novos grupos de trabalho foram contemplados por esses projetos, com expressiva diversificação das atividades desenvolvidas, como por exemplo as ligadas à construção civil, lapidação de pedras, preparo de doces e salgados etc.

Cabe indagar se os problemas anteriormente detectados foram teórica e praticamente resolvidos para que essas novas microunidades fossem implantadas. Uma análise dos projetos especiais no período referente à criação dessas novas microunidades 
de produção de bens e prestação de serviços revela primeiramente que, apesar do aumento significativo, não foram solucionados os problemas anteriormente apontados pela avaliação que se fez das primeiras unidades de produção; em segundo lugar, a criação de novas microunidades de produção e a elaboração de novos projetos a serem implementados nessa área não resultaram na formulação de uma política formalizada e assumida pelo Estado com relação ao setor informal do mercado de trabalho; finalmente, o aumento verificado implicou um incremento das situações problemáticas que foram e vêm sendo informalmente contornadas.

\section{Possibilidades e limitações no processo de expansão das microunidades}

Uma das questões a ser levantada, quando do estudo das limitações e dos espectos positivos de se atuar no setor informal, via criação de microunidades é a da viabilidade de expansão do número existente, já que esse aumento acarretaria não somente uma maior pressão para a solução dos problemas existentes como também um maior impacto sobre o mercado de trabalho, por envolver um número mais significativo de pessoas.

Isso vem de encontro a muitas críticas feitas a esse tipo de experiência por essas microunidades absorverem individualmente um número reduzido de trabalhadores. Entretanto, não se pode acreditar que uma ampliação do número de microunidades possa, por si só, fornecer os elementos para a superação de suas principais dificuldades devido ao aumento da pressão sobre o órgão estatal competente. É necessário que no próprio processo de expansão se procure superar os entraves detectados até o presente.

Dentre as dificuldades surgidas até então, três aparecem como primordiais: regulamentação jurídica, acesso à assistência previdenciária e comercialização.

A resolução do problema jurídico implicaria a possibilidade das microunidades surgirem sem estarem vinculadas a entidades sociais que possam imprimir-lhes um caráter assistencialista. Estariam ligadas diretamente a comunidades de base, tais como por exemplo associações de bairro. Tal regulamentação jurídica possibilitaria, por sua vez, o acesso à assistência previdenciária e a possibilidade de venda dos produtos com notas fiscais - fator que influencia positivamente no processo de comercialização.

O problema da comercialização está estritamente vinculado ao tipo de microunidade a ser cria- da. A escolha desse tipo liga-se, por sua vez, não somente às chances de competição do produto ou serviços no mercado, mas também à capacitação profissional da clientela a ser envolvida.

Com isso, é preciso que as pessoas recebam um treinamento que seja adequado às reais necessidades do mercado.

A experiência inicial demonstra que as microunidades surgiram em decorrência do término de cursos de treinamento, com a finalidade de se oferecer oportunidades de renda e trabalho aos elementos que os concluíram.

O que se procura ressaltar é a necessidade de que os cursos de treinamento surjam visando à criação das microunidades e não mais que essas venham a ser implantadas como forma de absorção de pessoas egressas de cursos de treinamento.

Para a definição do tipo de microunidade a ser estabelecida e, conseqüentemente, do curso de treinamento a ser oferecido, faz-se necessário uma pesquisa de mercado que consiga detectar as brechas possibilitadoras do consumo dos bens e produtos ofertados pelas microunidades.

Atualmente estão em funcionamento 44 microunidades e cerca de 144 serão implantadas pelos projetos especiais dentro do Programa Centros Intermediários. O primeiro passo efetuado foi elaborar pequisas que detectassem atividades informais já existentes nos diversos municípios e que absorvessem um número significativo de pessoas.

O que se verificou foi que as atividades predominantes variavam muito pouco entre os diversos municípios. No caso do trabalho exercido pelas muIheres, as atividades mais em evidência foram as de confecção e de lavagem de roupa; e no caso dos homens, as atividades ligadas à prestação de serviços na indústria de construção

A questão que se coloca é a da viabilidade de se ampliar o número de lavadeiras e costureiras em municípios onde o número de habitantes não é muito elevado e conseqüentemente onde a demanda seria limitada. Em municípios maiores, essa problemática seria inferior, mas ainda persistiria. Com base nesses dados, levanta-se o porquê de não se diversificar os tipos de microunidades com a introdução de novos cursos de treinamento que possibilitassem atividades até então desenvolvidas. Isso porém significaria mudanças culturais significativas que dificultariam ainda mais a experiência mas que nem por isso deveriam deixar de ser tentadas.

O que se nota, portanto, é que nesse processo de expansão se procurou dinamizar as atividades já existentes. Enfatizou-se a capacitação profissional com grande destaque e os cursos de treinamento 
passam então a ter como principal finalidade o aperfeicoamento profissional dos trabalhadores.

É a questão da garantia dos mercados que se levanta como a mais melindrosa. A comprovação de sua existência se fez pela própria presença dessas atividades. Se há lavadeira em grande quantidade e com muita roupa para lavar, é porque ela ainda é necessária; a mesma argumentação serve para justificar as demais atividades. Nada indica que haja mercado suficiente quando da ampliação dessas atividades.

A pesquisa de mercado até então efetuada se restringe a essa lógica e o que se procura agora enfatizar é a necessidade de uma mudança no próprio enfoque da pesquisa. Esta deveria ater-se mais ao próprio dinamismo do mercado, a fim de detectarse atividades que ao serem dinamizadas ou introduzidas viessem a ter sua demanda assegurada. A simples existência de atividades que absorvem um número elevado de pessoas não justifica por si só a viabilidade de expansão das mesmas, via criação de microunidades.

É necessário que se possa garantir a demanda. Além de ater-se mais ao dinamismo dos mercados, uma das saídas viáveis seria a própria participação do Estado no processo de comercialização, através, por exemplo, da formação de centrais de insumos que iriam baratear o preço do produto final ou, eventualmente, como comprador em potencial dos produtos e serviços.

Essa participação do Estado no processo de comercialização só poderia ocorrer caso esse assumisse tal experiência não apenas como um de seus vários programas, mas sim dentro de uma política de emprego onde a dinamização do setor informal fosse vista com maior atenção e destaque.

Muitos dos problemas presentes nas primeiras microunidades implantadas persistem ainda nas microunidades que estão sendo criadas. A urgência na tentativa de solucionar os problemas básicos se faz ainda maior por não se acreditar que um aumento numérico signifique sucesso na experiência. Pode muito mais significar uma expansão de problemas se nada se tentar fazer a fim de solucionar as dificuldades mais prementes.

\section{A proposta de centros de bairro}

Como se viu, a dupla função que as microunidades devem de início exercer - ou seja, atuar como meio de se criar associações ou cooperativas e funcionar como unidades produtivas - tem provocado uma das maiores dificuldades enfrentadas na operacionalização desse projeto.

Por um lado, na fase inicial de implantação, o grupo que compõe a microunidade carece de condições mínimas de organização e conscientização para a implantação de uma cooperativa ou associação. A microunidade é, nesse momento, o instrumento que propiciará o surgimento daquelas condições. Por outro, reafirmando o que foi dito, desprovida de personalidade jurídica definida a microunidade fica impossibilitada de receber os recursos que lhe são destinados pelo Estado para compra de equipamentos e matérias-primas, e não pode também comprar ou vender em grande escala já que não possui registros legais.

O Programa Estadual de Centros Intermediários, financiado em parte pelo Banco Interamericano de Desenvolvmento, incluiu, através de projeto da Secretaria de Trabalho e Ação Social, a proposta de implantação de 144 microunidades de produção no estado. Procurando contornar o problema de vinculação às entidades assistenciais e outros problemas tais como a precariedade de instalações, a falta de creches e outros serviços de apoio, a distância entre local de produção e residências dos trabaIhadores etc., foi criado dentro do programa um novo projeto denominado Centros de Bairros. Tal projeto, proposto pela Diretoria de Planejamento Social e Urbano da Fundação João Pinheiro, visa à implantação em Minas Gerais de 21 centros de bairro em 14 cidades de porte médio. Esses centros, que pretendem ser auto-sustentáveis, deverão atuar de forma a fornecer uma série de subsídios para tornar mais eficiente e eficaz o papel das microunidades.

Na verdade, a principal finalidade do centro de bairro é a de promover o fortalecimento da comunidade e de oferecer à população mais pobre, especialmente mulheres, condições adequadas para prestação de serviços e produção de bens, através de atividades informais.

Os centros de bairro contam, para isso, com salas de reuniões, serviços tais como telefone, chuveiros públicos, chafarizes, caixas de correio etc. e oficinas totalmente equipadas para produção de doces, roupas, artesanatos e para prestação de serviços de manicure, cabeleireiro, faxina etc. Esses benefícios são oferecidos através de uma estrutura de organização simples que se apóia em quatro núcleos de concentração de atividades: de coordenação e promoção, de serviços auxiliares, de instrumentos de trabalho e de apoio à produção e ao consumo.

O primeiro desses núcleos deverá ser responsável pela administração do centro, quer coordenando as ações desenvolvidas pelos outros núcleos, quer estabelecendo constantes ligações entre os diversos grupos profissionais encarregados dos vários setores para a participação de todos na administração do centro ou, seja ainda, facilitando as ligações desses grupos com instituições oficiais ou da própria comunidade. 
O segundo, núcleo de serviços auxiliares, deverá facilitar o acesso à documentação através de setores ligados às instituições oficiais responsáveis pela expedição de documentos ou o acesso a benefícios como telefones, caixas postais, chafarizes, sanitários públicos ou salas apropriadas que possam beneficiar as associações profissionais que necessitem de um local para atendimento de seus associados.

O núcleo de instrumento de trabalho, como o próprio nome indica, será formado por salas equipadas que deverão prover os instrumentos de trabalho necessarários a cada grupo profissional associado que participe da operacionalização do centro. Aí se localizam o que aqui temos denominado microunidades de produção.

Por último, temos o núcleo de apoio à produção e ao consumo, compondo-se de unidades produtivas - uma ou duas pequenas fábricas de tecnologia simplificada - que deverão constituir-se na principal fonte de recursos para a operação do centro. Essas fábricas poderão, de acordo com as necessidades e interesses da comunidade, produzir alimentos de baixo custo, artefatos de concreto, calçados etc. Além disso, esse núcleo deverá apoiar e incentivar atividades produtivas do tipo caseiro que surjam na comunidade e necessitem de apoio financeiro ou técnico. Esse núcleo não deverá ser, no entanto, a única fonte de recursos. O centro será mantido, também, por pequenas taxas pagas pelas microunidades e pelas mães que tiverem filhos nas creches. Esses recursos serão utilizados para o pagamento de todas as despesas de água, energia elétrica, limpeza, administração e manutenção de todas as atividades desenvolvidas pelo centro ou, inclusive, para eventuais ampliações de setores.

Como a guarda dos filhos foi uma das principais dificuldades apontadas pelos integrantes das microunidades, o projeto propõe como um de seus componentes a implantação de creches domiciliares financiadas pela FEBEM e FLBA. Com esse sistema alcançam-se vários objetivos: o primeiro, como já se mencionou, é liberar as mães para o trabaTho fora do lar, mais especificamente para o trabatho nas microunidades de produção; outro é fornecer alimentação e abrigo para as crianças de baixa renda; e um terceiro, é elevar diretamente a renda de mulheres que, não participando do trabalho nas microunidades, podem receber aquelas crianças em suas casas.

Os centros de bairro deverão ser construídos pelas prefeituras e doados às associações de bairro mais representativas da população, que vão administrá-loś e contarão com um órgão consultivo e normativo, o conselho comunitário. Este será formado por representantes da comunidade interna ao centro - microunidades, creches, fábricas - e da comunidade externa ligada a ele - associações de bairro, igrejas, instituições filantrópicas, CEAPS etc.

O centro contará, também, com um conselho fiscal que se incumbirá do acompanhamento das prestações de contas da administração do equipamento. A formação desses conselhos e sua regulamentação poderá facilitar a concessão de autorizações especiais para comercialização de mercadorias. No estado já foi concedido esse tipo de autorização a entidades civis sem fins lucrativos, desde que apresentem estruturação jurídica adequada.

Esse equipamento social, pelas características apresentadas, deverá proporcionar vantagens, significativas, tais como socialização das despesas e receitas, a homogeneização dos preços dos produtos e serviços, o repasse de experiências e conhecimentos e o aumento da produtividade através da divisão do trabalho e da existência de equipamentos mais adequados às atividades. Tudo isso deverá beneficiar não só produtores como consumidores de baixa renda dessas cidades.

Vale dizer que esses centros de bairro deverão constituir-se em um veículo de promoção social, de aglutinação e organização comunitária e de dinamização do mercado informal das cidades. Por essas razões, deverão ser implantados em áreas periféricas de alta densidade demográfica de baixa renda e deverão integrar-se a esse espaço físico e social, através de proposta arquitetônica simples, funcional e de baixo custo. Essa integração não poderá ser, no entanto, somente física, devendo concretizar-se, principalmente, a partir da transferência dos poderes de decisão e de gerência para a comunidade, por intermédio de suas formas associativas mais representativas.

\section{Notas}

1. GRANDI, Sonia L. \& Servilha, M. Tereza.Organiza ções e trabalho. Belo Horizonte, Fundação João Pinheiro/DPSU, 1980, n.p.

2. CAVALCANTI, Clóvis. Viabilidade do setor informal: a demanda de pequenos servicos no Grande Recife. Recife, Instituto Joaquim Nabuco de Pesquisas Sociais, 1978. 158p. (Estudos e Pesquisas), 11)

3. MINAS GERAIS. Secretaria de Estado do Trabalho, Ação Social e Desportos. Gerência de Projetos Especiais.Projetos Especiais/Belo Horizonte, 1979, n.p.

4. PELIANO, José Carlos. Setor informal ou pobreza ur bana? Fundação JP; análise e conjuntura, Belo Horizonte, 6(11): 33-8, nov. 1976.

5. PROGRAMA REGIONAL DEL EMPLEO PARA AMÉ RICA LATINA Y EL CARIBE, Santiago. Politicas hacia el sector informal urbano./Genebra/OIT, 1977. 19p. (PREALC, Documento de Trabajo, 116)

6. SEMINÁRIO SOBRE POLITICAS PARA O SETOR INFORMAL URBANO DO MERCADO DE TRABALHO, Salvador, 1977. Anais... Salvador, Secretaria do Trabalho e Bem Estar Social, 1977. 455p.

7. Entrevistas com o gerente do SINE e o diretor do Departamento de Trabalho da Secretaria de Estado do Trabalho, Ação Social e Desportos de Minas Gerais, realizadas em 1982.

8. Entrevistas com representantes de associações de bairros e lideranças informais. 